\title{
Energy and Minerals Science at the U.S. Geological Survey
}

The economy, national security, and standard of living of the United States depend on adequate and reliable supplies of energy and mineral resources. Based on population and consumption trends, the Nation's and World's use of energy and minerals is expected to grow, driving the demand for scientific understanding of resource formation, location, and availability. The importance of environmental stewardship and human health in sustainable growth emphasizes the need for a broader understanding of energy and mineral resources. The U.S. Geological Survey (USGS) is a world leader in conducting research needed to address these challenges and to provide a scientific foundation for policy and decisionmaking with respect to resource use, sustainability, environmental protection, and an adaptive resource management approach.

\section{Introduction}

The United States produces and uses substantial amounts of energy and mineral resources each year, and faces critical decisions regarding growing challenges in meeting current (2013) and future needs (fig.1). Decisions at every scale will affect the availability of energy and minerals and have far-reaching economic, environmental, geopolitical, and social consequences.

The need for energy and mineral resources is driving exploration and production into geological settings with limited or no data, such as in the Arctic, deeper in the Earth's crust, and beneath deeper regions of the oceans. Interest in alternative energy and mineral resources may involve producing unconventional resources, mining lower concentration deposits, recovering resources from waste and recycling streams, and sourcing from countries with different political systems or environmental stewardship philosophies. These demands are met with the need to consider energy and mineral development amidst the effects of climate change, the comparative value of ecosystem services, and the risks associated with natural hazards to prevent or mitigate environmental degradation. The USGS serves the national interest by providing impartial scientific studies (fig. 2) and information that enable decisionmakers and society to make informed decisions and to understand potential outcomes.

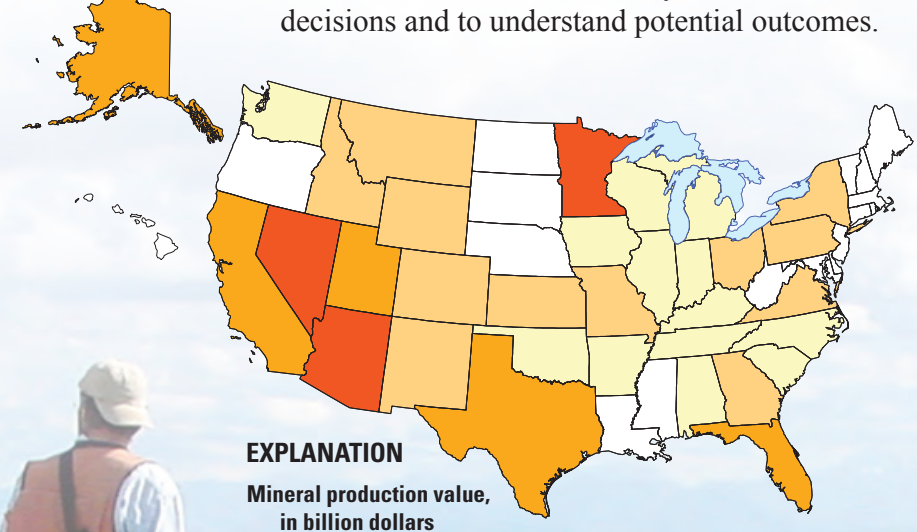
in billion dollars

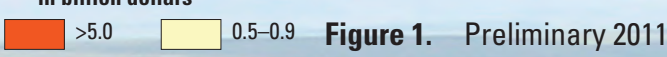
value of nonfuel mineral production by state. Data from the USGS National Minerals Information Center.

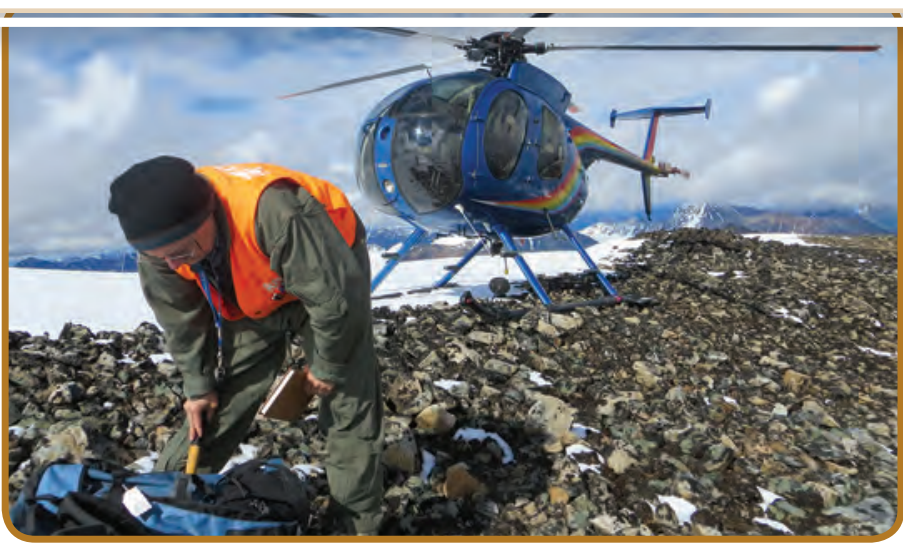

Figure 2. USGS scientist collecting rock samples as part of a regionalscale, geologic framework study of the western Alaska Range.

\section{The USGS Energy and Minerals Science Strategy}

In the USGS Energy and Minerals Science Strategy (http://pubs. usgs.gov/circ/1383d/), we identified a set of overarching questions that drive the science needed to provide information on existing and emerging energy and minerals issues during the coming decade:

- How or where might energy and mineral commodities be obtained to meet present and future needs?

- What economic, environmental, geopolitical, and health consequences must also be considered in both the short term and the long term?

- How can decisions more effectively incorporate scientific complexity and uncertainty?

- What science is needed to anticipate and respond to future events?

Using these questions as a guide, five interdependent goals were identified that recommend actions to provide the needed scientific research, information, and analysis:

- Goal 1.-Understand fundamental Earth processes that form energy and mineral resources.

- Goal 2.-Understand the environmental behavior of energy and mineral resources and their waste products.

- Goal 3.-Provide inventories and assessments of energy and mineral resources.

- Goal 4.-Understand the effects of energy and mineral development on natural resources and society.

- Goal 5.-Understand the reliability and availability of energy and mineral supplies. 
The unifying concept for these goals is a resource lifecycle for energy and minerals (fig. 3). The science actions developed in this strategy represent key components of integrated studies at multiple scales. When leveraged with expertise across the USGS and with partners, the actions in this strategy can provide a more comprehensive and integrated understanding of natural resources and facilitate the dissemination of science, information, and tools to a range of audiences, including policymakers, regulators, resource managers, scientists, and the public.

\section{Providing a Scientific Foundation for Decisionmaking}

The USGS, with its long history of important contributions to energy and mineral resources science, has a solid foundation of core capabilities. USGS scientists have broad expertise relevant to understanding energy and mineral formation and occurrence, resource assessment, environmental characterization, data collection, and analysis. Many congressional mandates and Executive orders recognize, support, and encourage USGS science. With this foundation and recognized expertise, the USGS is well positioned to continue providing cutting-edge science on current (2013) and future energy and mineral resources issues.

Mission and Vision.-The USGS energy and mineral resources mission is to provide impartial science and information for understanding the occurrence and distribution of national and global energy and mineral resources that may contribute to supplies; the potential environmental and socioeconomic effects associated with resource occurrence, extraction, and use; and the global supply and flow of nonfuel mineral commodities.

Over the coming decade, science leading to a broader understanding of the resource lifecycle will be a cornerstone for decisions supporting our Nation's economic vitality, protection of natural resources, security of resource supplies, and quality of life.

\section{Science Linkages}

Coordination within USGS and with partners is important to understand fully the breadth and magnitude of interactions among energy and mineral lifecycles and air, land, soil, water, ecosystem services (or natural capital), and human health from local, regional, national, and global perspectives. The USGS Energy and Minerals Science Strategy mirrors the reality that complex societal issues demand diverse capabilities from every corner of the USGS and its partner communities. Many science actions reflect the need for enlisting expertise across the USGS. Likewise, efforts precipitated by this strategy will contribute to other USGS science goals. An even broader range of linkages that includes partners, such as other DOI bureaus, Federal agencies, state geological surveys, and international organizations, is acknowledged and anticipated.

- The U.S. Geological Survey Energy and Minerals Science Strategy Planning Team: Richard C. Ferrero, Jonathan J. Kolak, Donald J. Bills, Zachary H. Bowen, Daniel J. Cordier, Tanya J. Gallegos, James R. Hein, Karen D. Kelley, Philip H. Nelson, Vito F. Nuccio, Jeanine M. Schmidt, and Robert R. Seal

Figure 3. A resource lifecycle (center) depicts a sequence of stages along which decisions are made in relation to energy and mineral occurrence, development, use, and disposition of waste. Although issues raised at specific stages can be very focused, the science needed to inform decisions is typically broad and interdisciplinary. Three USGS studies exemplify this relationship. Photos are (clockwise): a sample of uranium ore from the Pumpkin Buttes area, Wyoming; a landscape near Buffalo, Wyoming; and a wind farm in Illinois.
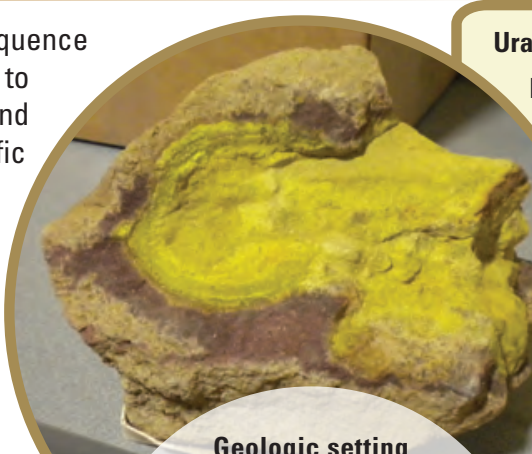

Uranium Resources and Environmental Health Assessment

National interest in expanded use of nuclear power is an issue that touches multiple stages of the resource lifecycle. The USGS is developing a science-based approach to complement a national uranium resource assessment and link multiple capabilities across biological, geological, and hydrological sciences. This broadened evaluation of uranium resources requires an understanding of geologic setting; extraction technologies; and processes affecting contaminant dispersion and biological uptake.

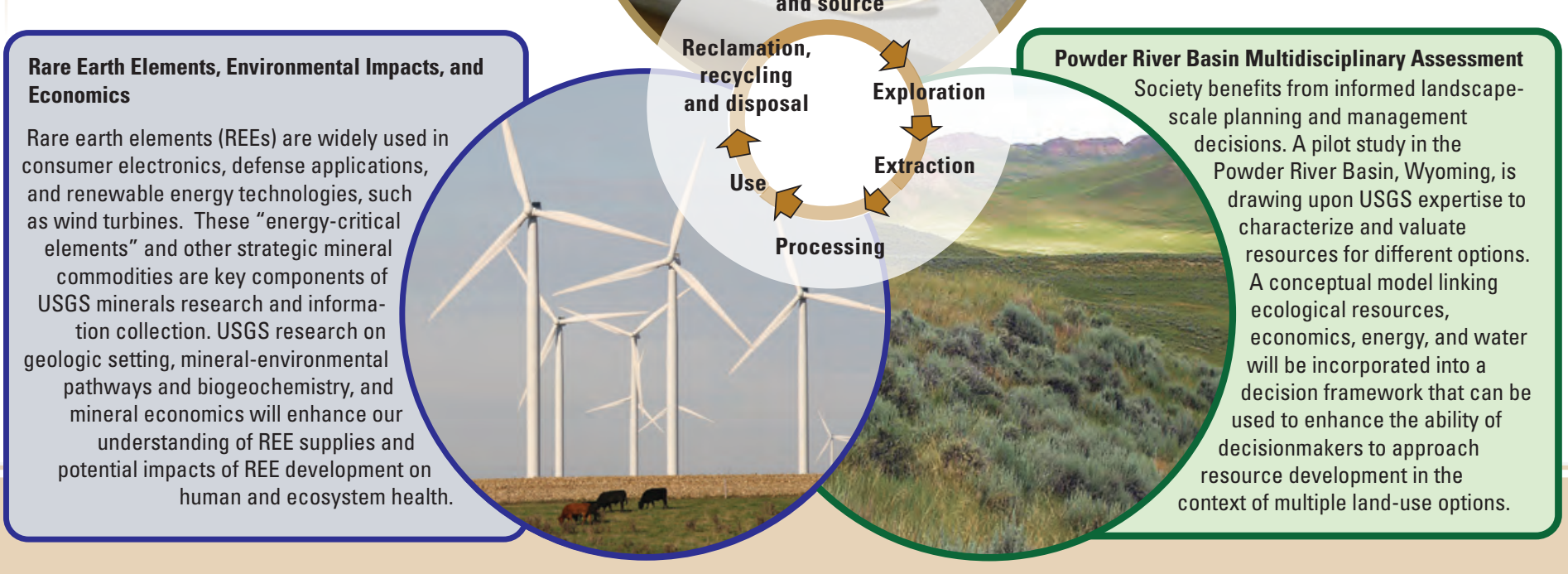

\section{For additional information:}

- USGS Energy and Mineral Resources Mission Area web sitehttp://www.usgs.gov/energy_minerals/

- USGS Energy and Mineral Resources Science Strategyhttp://pubs.usgs.gov/circ/1383d/
Contact information:

Office of the Associate Director, Energy and Minerals U.S. Geological Survey 12201 Sunrise Valley Drive Reston, VA 20192
ISSN 2327-6916 (print) ISSN 2327-6932 (online) http://dx.doi.org/10.3133/fs20133111 